\title{
In vivo treatment with anti-CD44 monoclonal antibody disrupts intracerebral progression of $\mathbf{C 6}$ glioblastoma
}

\section{Roger Breyer, Sami Hussein, M.D., Ph.D., Dorel L. Radu, M.D., Ph.D., Klaus-Martin Pütz, Sven Gunia, Hartmut Hecker, Ph.D., Madjid Samii, M.D., Ph.D., Gerhard F. Walter, M.D., Ph.D., and Alexandru C. Stan, M.D., Ph.D.}

Department of Microbiology, Mount Sinai School of Medicine, New York, New York; Institute of Neuropathology, and Departments of Neurosurgery and Biometrics, Hannover Medical School, Hannover, Germany; and Department of Cellular Immunology, Cantacuzino Institute, Bucharest, Romania

Glioblastoma multiforme (GBM) invasiveness is a complex process that involves recognition and attachment of GBM cells to particular extracellular matrix (ECM) molecules prior to migrating into proteolytically modified matrix and inducing angiogenesis. The CD44, which is a transmembrane adhesion molecule found on a wide variety of cells including GBM, has been suggested as the principal mediator of migration and invasion. The aim of the present study was to demonstrate whether an antibody specific to the standard form of CD44 (CD44s, 85-90 kDa) might prevent invasion and thus disrupt progression of C6 GBM in vivo.

Immunostaining demonstrated homogenous expression of CD44s on the surface of C6 GBM cells and tumors. Flow cytometric analysis demonstrated binding saturation of anti-CD44s mAb to the receptor at $1 \mu \mathrm{g} / 5 \times 10^{5}$ cells. Blocking of CD44s in vitro resulted in a dose-dependent progressive (up to $94 \pm$ 2.7\%; mean \pm standard deviation [SD]) detachment of C6 cells from ECM-coated culture surfaces. Blocking of CD44s in vivo resulted in significantly reduced C6 brain tumors $(3.6 \pm 0.4 \%$ [SD])--measured as the quotient: tumor surface $\left(\mathrm{mm}^{2}\right) /$ brain surface $\left(\mathrm{mm}^{2}\right)$ X 100--as compared with untreated $(19.9 \% \pm 0.9 \%)$ or sham-treated rats $(19.2 \pm 1.1 \%$ to $19.3 \pm 2.5 \%$ [SD]). Disruption of C6 GBM progression correlated with an improved food intake; treated rats were significantly less cachectic $(166.6 \pm 16.4 \mathrm{~g}[\mathrm{SD}])$ than those that were untreated $(83.0 \pm 2.7 \mathrm{~g}[\mathrm{SD}])$ or sham-treated $(83.4 \pm 1.1 \mathrm{~g}$ to $83.0 \pm 2.2 \mathrm{~g}[\mathrm{SD}])$ rats.

The authors conclude that CD44s-targeted treatment with specific mAb may represent an effective means for preventing progression of highly invasive GBMs.

Key Words * CD44 * glioblastoma * C6 * invasion * extracellular matrix * immunoinhibition

Cluster of differentiation 44 (CD44, Hermes-1, H-CAM) is a broadly distributed polymorphous family of 
cell membrane glycoproteins involved in cell-cell and cell-matrix adhesive interactions, which was initially described as the receptor of lymphocytes.[5,9,12,31,34,35,43] The CD44 molecule has been attributed to various functions: 1) development and differentiation of $\mathrm{T}$ and $\mathrm{B}$ cells; 2) activation molecule increased on the cell surface as a response to antigen stimulation; and 3) adhesion molecule involved in the heterotypic lymphocyte-endothelial cell-cell interaction, which mediates lymphocyte extravasation from blood into homing lymphoid organs.[14] The major role of CD44, acting as an adhesion molecule involved in cell motility, has further been demonstrated by the finding that CD44 functions as a receptor for hyaluronate (HA), a glycosaminoglycan that is a major component of the extracellular matrix (ECM).[1,28,31] The CD44 molecule is also known to bind to other components of the ECM such as fibronectin, collagen, chondroitin sulfate, laminin, and vitronectin. $[1,7,12,19,30]$ These binding properties of CD44 have been attributed to the standard form of the molecule (CD44s), the $80-\mathrm{kDa}$ isoform that lacks the sequences encoded by variant exons.

The CD44 is not only expressed on cells of the lymphoid compartment but is found in fetal and adult tissues of different ontogeny, including the central nervous system.[10,11,25,42] Close sequence homology between exons V1 to V10 obtained from mice, rats, and humans indicates a specific functional role rather than a purely structural role for the membrane proximal extracellular domain of the CD44 molecule.[37] Furthermore, analysis of recent data has proven the role of CD44 in neoplasia. When CD44s is transfected into melanoma or lymphoma cells, tumorigenicity is increased, and this is ECM binding dependent.[4,39] Within the nervous system, CD44 molecules have been localized on normal glial cells,[42] Schwann cells, and glial tumors, in some of which CD44 is overexpressed;[25] however, it has not been localized on neurons or oligodendrocytes.[11,32] The expression of CD44 appears to be maintained during tumorigenesis. $[3,8]$ This has prompted many investigations aimed at examining whether this molecule plays an important role in central nervous system neoplastic development, thus focusing on invasion and metastasis. Interestingly, a pan-CD44 antibody that recognizes all CD44 isoforms has been shown to block glioma cell invasiveness in vitro.[30]

In the present investigations we have endeavored to address an important biological property of glioblastoma multiforme (GBMs), namely their highly invasive behavior, which is a major factor in determining a lower treatment success rate than might be expected in tumors that almost never metastasize. In this process, the CD44 adhesion molecule is thought to have an important role in regulating the adhesive and locomotor properties of malignant glioma cells because, during invasion, homotypic adhesion is reduced with a concomitant increase in heterotypic adhesion.[36] Analysis of our results demonstrates, for the first time, that local treatment with an anti-CD44s monoclonal antibody can effectively inhibit glioma invasion, thus blocking tumor growth. Continuous delivery and long-term extracellular persistence of anti-CD44 antibodies efficiently disrupted glioma invasiveness and, therefore, tumor progression. The model used in this study is artificial, but although the specific intratumorally injected anti-CD44s monoclonal antibody most likely reacted with CD44s epitopes constitutively expressed on normal non-neoplastically transformed glial cells as well,[21] it did not affect the rats. On the contrary, treated animals developed less tumor-induced cachexia as compared with the controls, thus suggesting a protective effect of the treatment.

\section{MATERIALS AND METHODS}

\section{Tumor Cell Culture}

The GBM cell line C6 was cultured in culture flasks in Dulbecco's modified eagle medium (DMEM) and 
supplemented with $10 \%$ fetal calf serum, $100 \mu \mathrm{g} / \mathrm{ml}$ streptomycin, and $100 \mathrm{U} / \mathrm{ml}$ penicillin. Cells were routinely kept in culture in a standard humidified incubator at $37^{\circ} \mathrm{C}$ in a $5 \% \mathrm{CO}_{2} / 95 \%$ air atmosphere. At subconfluence, the culture medium was discarded, cells were washed once in sterile Dulbecco's phosphate-buffered saline (PBS), harvested by trypsinization for 5 minutes at $37^{\circ} \mathrm{C}$, and the cell suspension was collected in 50-ml tubes. After centrifugation for 10 minutes at $1400 \mathrm{rpm}$ and $4^{\circ} \mathrm{C}$, cells were resuspended in $6 \mathrm{ml}$ DMEM complete medium. Cell density and viability were determined by the standard hemocytometric counting of trypan blue-excluding cells in a hemocytometer by using an inverted Zeiss Axioplan microscope.

\section{Preparation of Coverslips}

Round 18-mm-diameter glass coverslips and round 25-mm-diameter coarse filter papers layered alternately to form a stack were introduced in a 50-ml tube. The stack was thoroughly washed in 100\% ethanol and then air dried. The stack was then immersed in a $2 \mathrm{~N} \mathrm{NaOH}$ solution and incubated at room temperature overnight. The following day, the $\mathrm{NaOH}$ solution was discarded, and the stack was rinsed thoroughly with tap water. The stack was immersed in PBS and incubated at room temperature overnight. This procedure removes residual acidity on the surface of the glass coverslips which improves adherence of cultured cells. The stack was again rinsed extensively with tap water, then in double-distilled water, and finally immersed in $100 \%$ ethanol. After complete air drying, the coverslips were gamma-irradiated at 20,000 rad and aseptically distributed into 12-well plates. The coverslips were coated overnight with $1 \mu \mathrm{g} / \mathrm{cm}^{2}$ laminin in sterile PBS. After removing the coating solution, the 12-well plates were kept sterile in the incubator.

\section{Culture of Cells on Coverslips}

After counting and determining viability, cells were diluted in DMEM complete medium at a final concentration of 1 X 106/ml and kept on ice until inoculation. Cells were inoculated at 5 X $10^{4} /$ well onto the previously prepared glass coverslips and kept in culture for 3 days. The culture medium was then discarded, and the coverslips were rinsed three times with PBS to remove culture medium completely. Finally, the coverslips were fixed in a $1: 1$ methanol/acetone mixture at $-20^{\circ} \mathrm{C}$ for 10 minutes. After discarding the fixative mixture, the coverslips were air dried overnight.

\section{Preparation of Antibodies}

Mouse anti-CD44s monoclonal antibody and an isotype control $\mathrm{IgG}_{1}$ were dialyzed for 24 hours at $4{ }^{\circ} \mathrm{C}$ to remove cytotoxic $\mathrm{NaN}_{3}$ (sodium azide) ions. Dialysis was performed in 1-kDa disposable dialyzers against sterile PBS. Antibody solutions were collected, and protein concentrations were measured spectrophotometrically by absorbance at $280 \mathrm{~nm}$. After adjusting the concentration of both antibodies at $0.64 \mu \mathrm{g} / \mu \mathrm{l}$, aliquots of $50 \mu \mathrm{l}$ were frozen and kept at $-20^{\circ} \mathrm{C}$ until use.

\section{Cytotoxicity Assay}

The putative cytotoxic effect of anti-CD44s mAb and isotype control $\mathrm{IgG}_{1}$ was assessed using a non-radioactive cell proliferation and cytotoxicity assay. After counting and determining viability, $2 \mathrm{X}$ $10^{3}$ cells/well were incubated in a 96-well plate in DMEM complete medium, in the presence of 20 $\mu \mathrm{l} /$ well dye substrate, according to the manufacturer's instructions. Anti-CD $44 \mathrm{~s} \mathrm{mAb}$ or isotype control $\mathrm{IgG}_{1}$ was added to the wells as follows: $2 \mu \mathrm{g} / \mathrm{well}, 8 \mu \mathrm{g} / \mathrm{well}$, or $20 \mu \mathrm{g} / \mathrm{well}$ and further incubated for 5 
hours. Controls were incubated under the same conditions but in the absence of antibodies. Finally absorbance was measured at $450 \mathrm{~nm}$ with $620 \mathrm{~nm}$ as a reference. Assays were performed in triplicate.

\section{Adhesion Assay}

Sterile glass coverslips were coated overnight with $1 \mu \mathrm{g} / \mathrm{cm}^{2}$ laminin or fibronectin, or with $5 \mu \mathrm{g} / \mathrm{cm}^{2}$ collagen, in sterile PBS. Coating solutions were removed and the 12-well plates were kept sterile in the incubator. Cells were inoculated at $5 \times 10^{4}$ /well onto the glass coverslips and kept in culture for 18 hours (initial adhesion and proliferation). Thereafter, anti-CD44s $\mathrm{mAb}$ or isotype control $\mathrm{IgG}_{1}$ was added to the wells as follows: $1.28 \mu \mathrm{g} / \mathrm{well}, 2.56 \mu \mathrm{g} / \mathrm{well}, 5.12 \mu \mathrm{g} / \mathrm{well}, 7.68 \mu \mathrm{g} / \mathrm{well}, 10.24 \mu \mathrm{g} / \mathrm{well}$, and $12.8 \mu \mathrm{g} / \mathrm{well}$, and cells were cultured for another 18 hours in the presence of antibodies. Controls were cultured under the same conditions but were not treated with antibodies. Culture medium was discarded and coverslips fixed as described. Assays were performed in triplicate.

\section{Surgical Procedure}

Fifty-five congenitally athymic, adult male and female nude rats weighing 158 to $183 \mathrm{~g}$ were used. Rats were kept initially in groups of three, housed in sterile cages, and given free access to food and water (according to federal and government regulations). Intraperitoneal administration of anesthesia was induced using $0.05 \mathrm{ml}$ Rompun $2 \%$ supplemented with $0.15 \mathrm{ml}$ Ketanest $10 \%$. Stereotactic surgery was performed under sterile conditions using a stellar stereotaxic instrument for rats and a technique previously described.[38] Briefly, a 1.5-mm burr hole was drilled over the right frontal lobe of the rat, 2 $\mathrm{mm}$ to the right of the sagittal suture. After reflection of the periosteum a polyethylene-silicone device (4 $\mathrm{mm}$ cross diameter, $2 \mathrm{~mm}$ thickness) was affixed to the skull, to be used for later local intracerebral injections in the treated rats to control accurately the depth of instilled solutions while minimizing tissue damage. In the center of the device, a thin polyethylene-silicone tube (outer cross diameter $1.2 \mathrm{~mm}$ ) was welded to protrude $2 \mathrm{~mm}$ intracortically into the rat brain. Cells to be injected into rat brain were prepared as previously described and finally resuspended in sterile PBS (instead of DMEM complete medium). Initially a 50- $\mu$ l suspension containing $5 \times 10^{4}$ cells was slowly injected using a syringe that had been adapted to the device's extracranial aperture. Afterward, the device's opening was sealed with a droplet of bone wax to prevent reflux, and the skin was sutured. After surgery, rats were kept in individual cages. They were monitored for hydration and nutritional status on a daily basis throughout the study. Eleven groups of five rats each were randomly formed at the start of the experimental phase (Table 1). 


\begin{tabular}{|cccc|}
\hline \multicolumn{5}{c|}{ TABLE 1 } \\
\hline \hline Eat Group p* & C6 cells & \multicolumn{1}{c|}{ Treatment } & Timepoint (days) \\
\hline K1 & + & - & 7 \\
K2 & + & - & 14 \\
K3 & + & - & 21 \\
T1 & + & anti-CD44s mAb & $7,10,12$ \\
T2 & + & control lgG & $7,10,12$ \\
T3 & + & PBS & $7,10,12$ \\
A1 & - & anti-CD44s m Ab & $7,10,12$ \\
A2 & - & control lgG & $7,10,12$ \\
C1 & - & none & 7 \\
C2 & - & none & 14 \\
C3 & - & none & 21 \\
\hline There mere five rats in each group. & \\
\hline
\end{tabular}

\section{Treatment Protocol}

To determine growth kinetics of brain tumors in absence of treatment, rats were killed on Days 7, 14, and 21 following transplantation of cells (Groups K1, K2, and K3; Table 1). One week posttransplantation of cells, rats within three groups were treated with anti-CD44s mAb (Group T1), sham-treated with isotype control $\mathrm{IgG}_{1}$ (Group T2), or sham-treated with PBS (Group T3), respectively (Table 1); three treatments were given on Days 7, 10, and 12, respectively. Anti-CD44s mAb or isotype control $\mathrm{IgG}_{1}$ was applied at $32 \mu \mathrm{g} / 50 \mu \mathrm{l} / \mathrm{dose}$, and PBS was applied at $50 \mu \mathrm{l} /$ dose. All treated rats were sacrificed on Day 14 . The effect of anesthesia and treatment on rats was assessed by implanting polyethylene-silicone devices in the absence of $\mathrm{C} 6$ cells, and by induction of anesthesia as well as by performing anti-CD44s mAb or isotype control $\mathrm{IgG}_{1}$ instillations at the same timepoints as in the C6-tumor transplanted rats (Groups A1 and A2; Table 1). Control rats (on Days 7, 14 or 21 following the start of the experimental phase) were simply monitored for food and water intake in the absence of anesthesia, tumor transplantation, and treatment (Groups C1, C2, and C3; Table 1).

\section{Preparation of Histological Samples}

For preparation of the brains, a thin butterfly catheter was sutured in the abdominal aorta, and the inferior vena cava was opened. Rats were initially perfused with $60 \mathrm{ml}$ PBS supplemented with $30,000 \mathrm{U}$ heparin. Thereafter, rats were perfused with $60 \mathrm{ml}$ buffered formalin solution for in situ fixation. Brains were then removed from the skulls, dissected under a stereomicroscope at a total magnification of X 6.3 to $\mathrm{X} 40$, and cut into 3-mm-thick slices, starting from the initial canal of transplantation. Brain slices were further fixed in buffered formalin for another 2 days. Brain slices were then dehydrated using 50\%, $70 \%, 90 \%$, and $100 \%$ ethanol. After treatment with acetone, the slices were embedded in paraffin (56-58 ${ }^{\circ} \mathrm{C}$ melting point), and $7-\mu \mathrm{m}$ sections were cut. For each rat, five separate samples were analyzed. Routine histological examination of consecutive slices was performed with hematoxylin and eosin stain.

\section{Flow Cytometric Analysis}

To determine the binding saturation of the anti-CD44 mAb, cells were grown as described, harvested at subconfluence by trypsinization, centrifuged, and resuspended in fresh complete cell culture medium. Cells were kept for 45 minutes in the tissue-culture incubator. After counting, 1 X $10^{5}$ cells per sample were first washed with ice-cold PBS 1\%-bovine serum albumin (BSA) centrifuged, and the pellet 
resuspended in $100 \mu \mathrm{l}$ PBS 1\%-BSA containing anti-CD44s mAb $(1 \mu \mathrm{g}, 2 \mu \mathrm{g}$, or $5 \mu \mathrm{g})$ or in $100 \mu \mathrm{l}$ PBS $1 \%$-BSA containing isotype control $\mathrm{IgG}_{1}$ at same concentrations. After 30 minutes of incubation on ice, cells were washed in PBS 1\%-BSA, centrifuged, and the pellet resuspended in $100 \mu \mathrm{PBS} 1 \%$-BSA containing $2 \mu \mathrm{g}$ fluorescein (FITC)-goat anti-mouse $\mathrm{F}\left(\mathrm{ab}^{\prime}\right)_{2}$. After incubation on ice for 30 minutes, cells were washed in PBS 1\%-BSA, centrifuged, and the pellet fixed with $500 \mu \mathrm{l} 1 \%$-paraformaldehyde. Fluorescence intensity among 5000 cell events was determined by flow cytometric analysis by using an analyzer equipped with an air-cooled argon ion laser (emitting at $488 \mathrm{~nm}, 280 \mathrm{~V}, 15 \mathrm{~mW}$ ) with a standard optical configuration. Forward-angle and side-scatter light signals were collected for gating purposes. Fluorescence intensity was measured using $530 \pm 15 \mathrm{~nm}$ (SD) bandpass filter that gives an optimum detection for FITC.

\section{Immunocytochemical and Immunohistochemical Procedures}

For all immunocytochemical staining procedures, fixed cells on glass coverslips were first rehydrated in PBS for 10 minutes at room temperature. To detect the presence of CD44s, cells were incubated with 5 $\mu \mathrm{g} / 600 \mu \mathrm{l} /$ well anti-CD44s mAb in PBS 1\%-BSA for 1 hour at room temperature. Cells were rinsed twice with PBS and then incubated with $5 \mu \mathrm{g} / 600 \mu \mathrm{l} /$ well FITC-goat anti-mouse $\mathrm{F}\left(\mathrm{ab}^{\prime}\right){ }_{2}$ secondary antibody in PBS 1\%-BSA for 1 hour at room temperature in the dark. Cells were rinsed twice with PBS and then incubated with $3 \mu \mathrm{g} / 600 \mu \mathrm{l} /$ well RNAse A in PBS for 30 minutes at $37^{\circ} \mathrm{C}$ to remove ribonucleic acids completely. After rinsing twice with PBS, cells were stained with $2 \mu \mathrm{g} / 600 \mu \mathrm{l} /$ well propidium iodide in PBS for 30 minutes at room temperature in the dark. After rinsing twice with PBS and once with double-distilled water, coverslips were mounted cell-side down onto black mask single-circle cytoslides by using $15 \mu \mathrm{l}$ mounting medium. After 15 minutes air drying at room temperature in the dark, the mounted coverslips were sealed with $100 \mu \mathrm{l}$ Permount. Mounted specimens were analyzed using an inverted confocal laser scanning microscope at X 100 magnification (oil immersion objective) equipped with an appropriate fluorescence filter set for simultaneous double excitation (488/568 nm). Control staining was performed using the isotype control $\mathrm{IgG}_{1}$ as the primary antibody and the $\mathrm{F}\left(\mathrm{ab}^{\prime}\right)_{2}$ antibody as secondary antibody.

To assess the inhibition of adhesion, cells were incubated with $5 \mu \mathrm{g} / 600 \mu \mathrm{l} /$ well anti-vimentin in PBS 1\%-BSA for 1 hour at room temperature. Cells were rinsed twice with PBS and then incubated with 5 $\mu \mathrm{g} / 600 \mu \mathrm{l} /$ well Cy3-goat anti-mouse $\mathrm{F}\left(\mathrm{ab}^{\prime}\right)_{2}$ secondary antibody in PBS 1\%-BSA for 1 hour at room temperature in the dark. Cells were rinsed twice with PBS, the nuclei were counterstained with $2 \mu \mathrm{g} / 600$ $\mu 1 /$ well 4,6-Diamidino-2-phenylindole (DAPI) in PBS, and the coverslips were mounted as described. Mounted specimens were analyzed at X 20 magnification by using an upright Zeiss Axiophot microscope, and cell bodies were counted over the entire surface of the coverslips.

For all immunohistochemical staining procedures, tissue samples were deparaffinized and rehydrated as for routine histological analysis. To detect the presence of CD44s, samples were first antigen-retrieved according to a standard protocol. Briefly, samples were boiled in a microwave oven at $800 \mathrm{~W}$ power in $0.01 \mathrm{M}$ tri-sodium-citrate monohydrate buffer, $\mathrm{pH}$ 6.0, $2 \mathrm{X}$ for 5 minutes. After cooling, samples were extensively rinsed with PBS, and immunostained for CD44s; the nuclei were counterstained and mounted as described. Mounted specimens were analyzed using the inverted Leica confocal laser scanning microscope at X 100 magnification (oil immersion objective).

\section{Morphometrical Analysis and Quantification}


For morphometrical analysis of the tumor samples we used a technique previously described.[38] Briefly, consecutive slices, cut at $7 \mu \mathrm{m}$ each were evaluated microscopically to detect the greatest planar extension of the tumor. A charged-coupled device color camera adapted to a stereomicroscope was used to scan hematoxy and eosin-stained brain slices at a total magnification of X 6.3. The software used was Autoscope/Autoscale. Tumor and brain surfaces were traced in square millimeters after previous calibration of the system by using a standard $\mu$-slide. Tumor growth was traced as the quotient:

$$
\frac{\text { tumor sufface }\left(\mathrm{mm}^{2}\right)}{\text { brain sufface }\left(\mathrm{mm}^{2}\right)} \times 100
$$

\section{Statistical Analysis}

Statistical analysis was performed using a standard computer software package. The variables defined were the percentage of tumor area and body weight. Analysis of variance was used to compare differences in tumor progression and body weight among the different groups formed (Table 1). We compared the treated rats (Groups T1, T2, and T3), control rats (Groups C1, C2, and C3), untreated rats (Groups K1, K2, K3), and anesthesia-treated control rats (Groups A1 and A2). Data were pooled from all rats within the same group. For each variable, t-tests (least significant difference) were performed, with least significant difference equal to 0.2344. Statistical significance was set at a $p$ value less than 0.05 .

\section{Sources of Supplies and Equipment}

The GBM cell line C6 (CLL-107) was purchased from American Type Culture Collection (Rockville, MD) and cultured in T75 culture flasks obtained from Becton Dickinson (Bedford, MA) with DMEM provided by Gibco BRL (Gaithesburg, MD) and supplemented with fetal calf serum, streptomycin, and penicillin (Gibco BRL).

The cell density and viability were determined by hemocytometric counting with trypan blue-excluding cells obtained from Sigma Chemical Co. (St. Louis, MO) in a Reichert hemocytometer (Fisher Scientific, Springfield, NJ) and analyzed under an Axioplan miscroscope acquired from Carl Zeiss (Jena-Götingen, Germany).

We obtained the mouse anti-CD44s monoclonal antibody, the isotype control $\operatorname{IgG}_{1}$, the disposable dializers, and the RNAse A from Sigma Chemical Co. The non-radioactive cell proliferation and cytotoxicity assay (model EZ4U) was obtained from Biomedica (Vienna, Austria). The nude mice $\left(\mathrm{Nznu}^{++}\right)$were acquired from the Central Laboratory for Animal Breeding (Hannover, Germany). Used to induce anesthesia in the mice, the Rompun was obtained from Bayer Corporation (Shawnee Mission, KS) and supplemented with Ketanest, which was purchased from Fort Dodge Laboratories, Inc. (Fort Dodge, IO). The FITC-goat anti-mouse $\left(\mathrm{F}\left[\mathrm{ab}{ }^{\prime}\right]_{2}\right)$ antibody and the Cy3-goat anti-mouse (f[ab' $]_{2}$ ) were manufactured by Jackson ImmunoResearch Laboratories, Inc. (West Groove, PA). The Permount used to seal the mounted coverslips was obtained from Fisher Scientific.

The centrifuger (model RT7) was manufactured by Sorvall Products, L.P. (Newtown, CT). The spectophotometer used to measure protein concentrations is made by Hitachi Instruments, Inc. (Danbury, CT). In the cytotoxicity assays, absorbance was measured using the Microplate Reader, which was obtained from Bio-Rad (Hercules, CA). Fluorescence intensity was measured using an analyzer (model EPICS Profile II) purchased from Coulter Corporation (Hialeah, FL). The confocal laser scanning miscoscope was acquired from Leica Lasertechnik (Heidelburg, Germany). The charged-coupled device 
color camera (Sony Gmbh, Broadcast and Communication, Cologne, Germany) was adapted to fit a stereomicroscope, which was acquired from Wild Leitz (Heerbrugg, Switzerland). The software (Autoscope/Autoscale) used in the morphometric analysis and quantification was obtained from Digithurst (Nurnberg, Germany), and the computer software package (model SPSS/PC + Version 7.0) used in the statistical analysis was obtained from SPSS International BV (Gorinchem, The Netherlands).

\section{RESULTS}

\section{Immunodetection of CD44s}

Immunodetection of CD44s on cell membranes in vitro as well as within intracerebral tumors showed strong expression of the antigen (Fig. $1 \mathrm{a}$ and b). Membrane distribution was homogenous--that is, there was no clustering of stronger or weaker CD44s-expressing cells. Expression of CD44s in intracerebral tumors was similar on Days 7, 14, and 21 following initial transplantation.
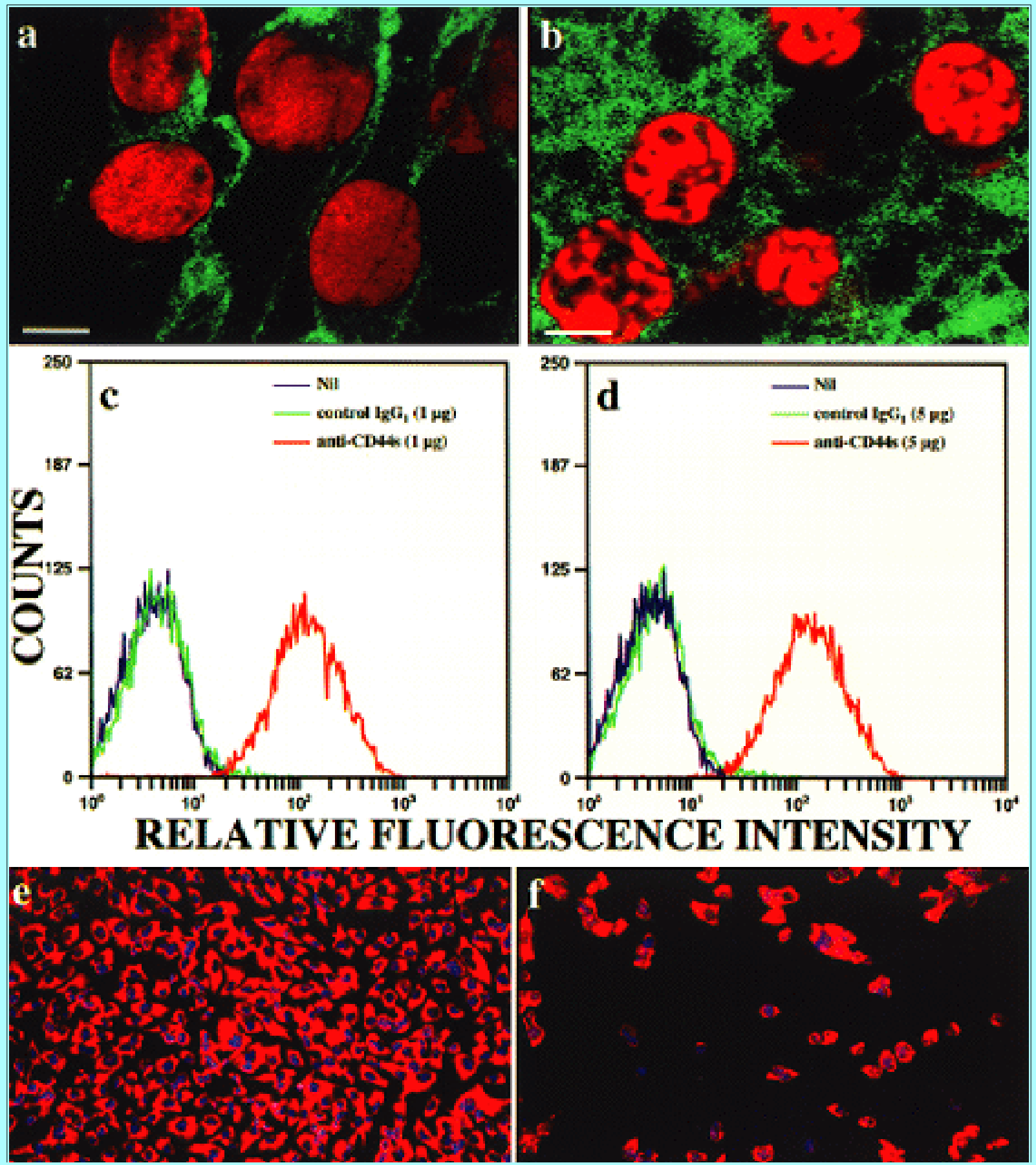


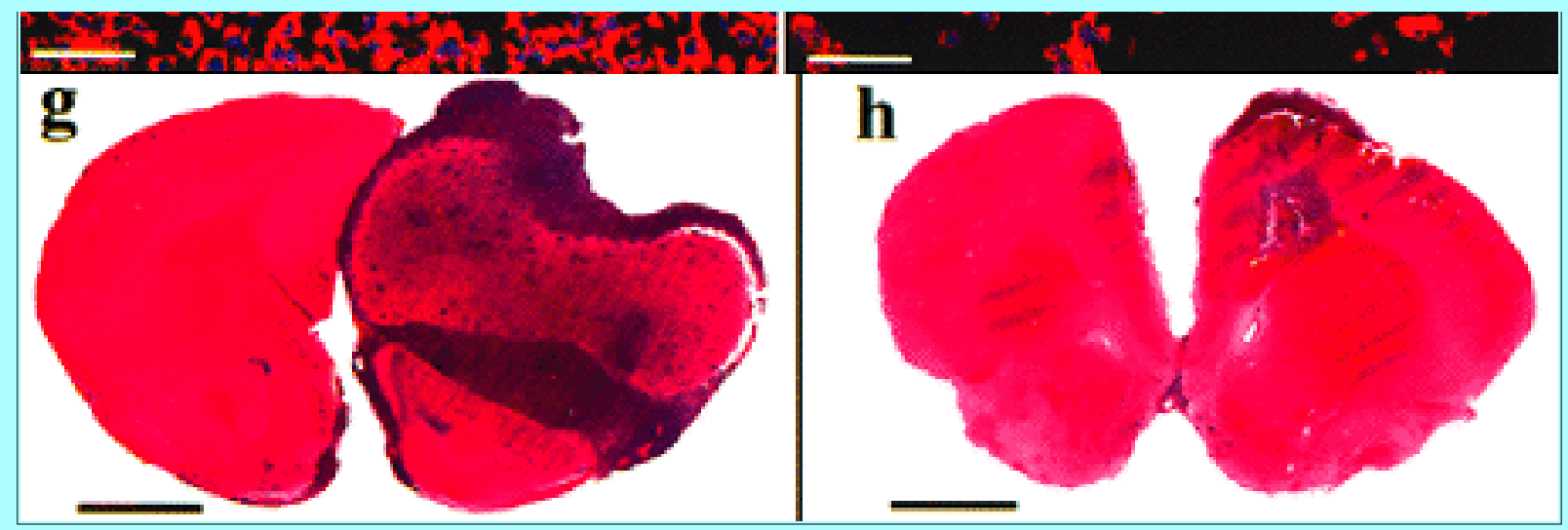

Fig. 1. Expression and blocking of CD44s by monoclonal antibody in vitro and in vivo. a: Immunodetection of CD44s on the membranes of C6 cells that were cultured on coverslips showing homogenous expression. Tumor cell nuclei were counterstained with propidium iodide. Scale bar $=1 \mu \mathrm{m}$. b: Immunodetection of CD44s in intracerebral C6 tumors on Day 14 after initial transplantation showing homogenous expression. Tumor cell nuclei were counterstained with propidium iodide. Scale bar $=1 \mu \mathrm{m}$. c: Graph showing detection of CD44s on the membrane of C6 cells by flow cytometric analysis (FACS) in which $1 \mu \mathrm{g}$ anti-CD44 mAb was used for staining $5 \times 10^{5}$ cells. This concentration was sufficient to saturate binding capacity of the ligand. Blue line = autofluorescence; green line = isotype control $\operatorname{IgG}_{1}(1 \mu \mathrm{g})$; red line $=$ anti-CD44 mAb $(1 \mu \mathrm{g})$. d: Graph showing that anti-CD44 $\mathrm{mAb}$ at 2 or $5 \mu \mathrm{g}$ demonstrated similar results. e: Inhibition of adhesion of C6 cells after 18 hours of cell culture scored $0 \%$ of detached cells at $1.28 \mu \mathrm{g} / \mathrm{well}$ or $2.56 \mu \mathrm{g} / \mathrm{well}$ of anti-CD44s mAb. Similarly, no inhibition of cell adhesion to the coverslip could be detected in the case of incubation with isotype control $\mathrm{IgG}_{1}$, even at the highest concentration of 12.8 $\mu \mathrm{g} /$ well. Scale bar $=5 \mu \mathrm{m}$. f: Inhibition of adhesion of C6 cells after 18 hours of cell culture scored $94 \pm 2.7 \%$ of detached tumor cells at $12.8 \mu \mathrm{g} /$ well of antiCD $44 \mathrm{~s} \mathrm{mAb}$. Scale bar $=5$ $\mu \mathrm{m}$. g: Brain slice of a rat transplanted with C6 cells on Day 21 in the absence of treatment (Group K3). Infiltration of the brain and invasive growth of the tumor starting from the transplantation site showed midline shift and interstitial hemorrhage. Scale bar $=2.2 \mathrm{~mm}$. h: Brain slice of a rat transplanted with C6 cells and treated with three successive doses $(32 \mu \mathrm{g}$ each) of anti-CD44s mAb on days 7, 10, and 12 following initial transplantation (Group T1) showing a significantly smaller tumor. Scale bar $=2.2 \mathrm{~mm}$.

\section{Flow Cytometric Analysis}

Detection of CD44s on cell membranes in which 1, 2, or $5 \mu \mathrm{g}$ anti-CD44 mAb for staining $5 \mathrm{X} 10^{5}$ cells was used, showed that $1 \mu \mathrm{g} \mathrm{mAb}$ was sufficient to saturate the binding capacity of the ligand (Fig. $1 \mathrm{c}$ ). The relative fluorescence intensity of unlabeled cells (autofluorescence) was 0.39 , cells incubated with isotype control $\operatorname{IgG}_{1}(1 \mu \mathrm{g})$ showed a relative fluorescence intensity of 0.42 , and cells incubated with anti-CD44s mAb $(1 \mu \mathrm{g})$ showed a relative fluorescence intensity of 11.94. Anti-CD44 mAb at 2 or $5 \mu \mathrm{g}$ showed similar results (Fig. $1 \mathrm{~d}$ ).

\section{Adhesion Assay}

After 18 hours of cell culture in the presence of graded concentrations of anti-CD44s mAb, inhibition of adhesion scored $0 \%$ detached cells at $1.28 \mu \mathrm{g} /$ well or $2.56 \mu \mathrm{g} /$ well (Fig. $2 \mathrm{~d}$ ). At $5.12 \mu \mathrm{g} /$ well, $11 \pm 2.1 \%$ 
(SD) of the cells were detached from the coverslip (Fig. 2 d), as compared with the controls. At 7.68 $\mu \mathrm{g} /$ well or $10.24 \mu \mathrm{g} /$ well, $31 \pm 3.1 \%$ (SD) to $59 \% \pm 2.9 \%$ (SD) of the cells were detached from the coverslips, respectively (Fig. 2 d). At $12.8 \mu \mathrm{g} /$ well, $94 \pm 2.7 \%$ (SD) of the cells were detached from the coverslip (Fig. $1 \mathrm{f}$ and Fig. $2 \mathrm{~d}$ ), as compared with the controls. Inhibition of cell adhesion by anti-CD44s $\mathrm{mAb}$ to the precoated coverslips was similar for all three components of the ECM (extracellular matrix) used (laminin, fibronectin, or collagen). No inhibition of cell adhesion to the coverslips could be detected in the case in which cells were incubated with same concentrations of isotype control $\mathrm{IgG}_{1}$, even at the highest dose of $12.8 \mu \mathrm{g} /$ well (Fig. $1 \mathrm{e}$ ).

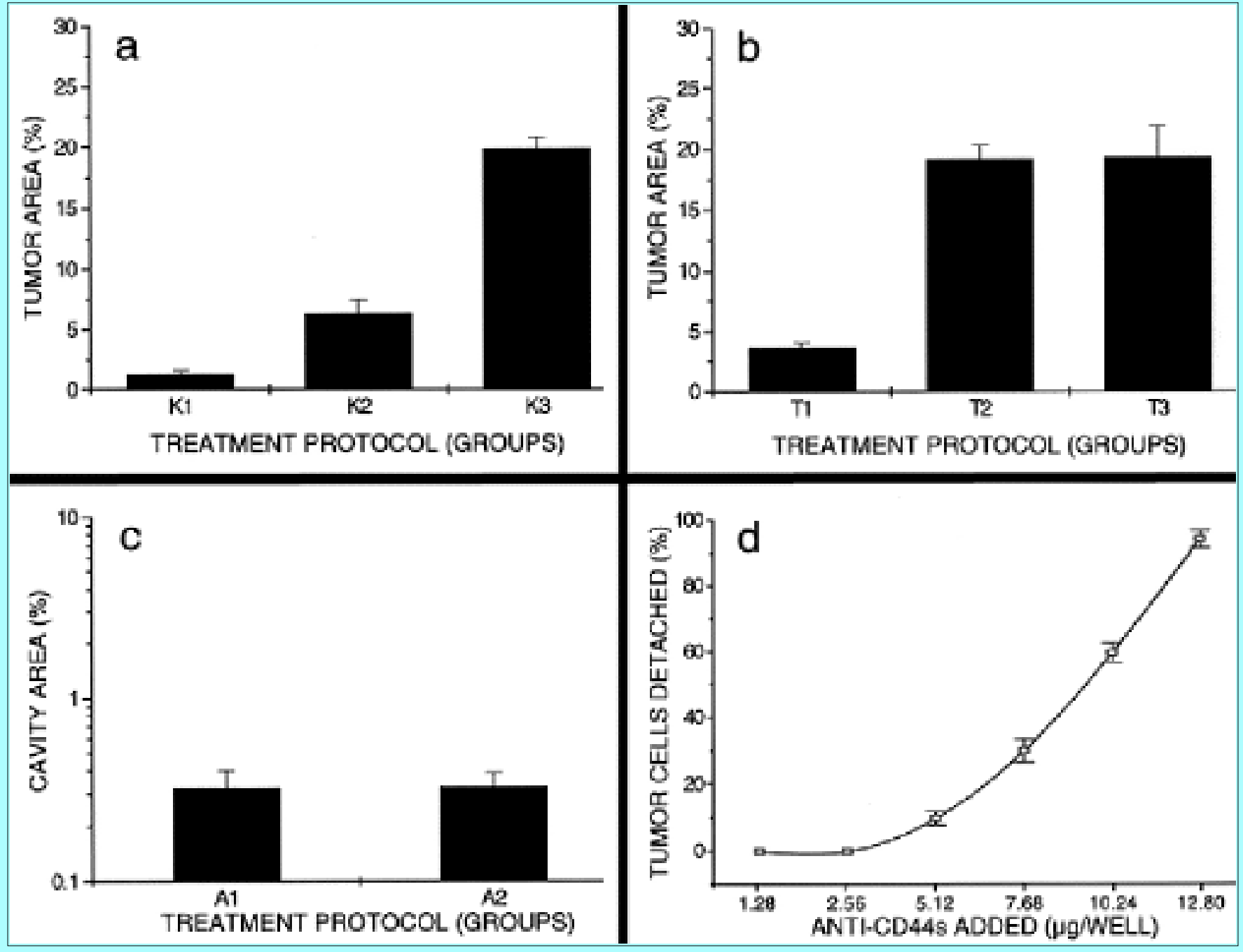

Fig. 2. Graphs showing the disruption of intracerebral progression of C6 GBM and in vitro blocking of C6 cell adhesion by anti-CD44s monoclonal antibody. Values are expressed as the mean \pm SD. Statistical significance was set at $p$ is less than 0.05 . a: Tumor progression in the growth-kinetics groups, K1, K2, and K3 (7, 14, and 21 days following initial transplantation in the absence of treatment), showing typical exponential growth: $1.3 \pm 0.3 \%$ on Day 7, $6.3 \pm 1.1 \%$ on Day 14 , and $19.9 \pm 0.9 \%$ on Day 21 . b: Tumor progression in the treatment groups, T1, T2, and T3, on Day 14 following initial transplantation. In rats in Group T1, which were treated with three successive doses (32 $\mu \mathrm{g}$ each) of anti-CD44s mAb on Days 7,10 , and 12 following initial transplantation significantly smaller tumors $(3.6 \pm$ $0.4 \%$ ) are shown on Day 14 as compared with the tumors of the untreated rats in Group K2 $(6.3 \pm 1.1 \%)$, or the sham-treated rats in Groups $\mathrm{T} 2$ and $\mathrm{T} 3$ (isotype control $\mathrm{IgG}_{1}$ treated, $19.2 \pm 1.1 \%$ and PBS treated, $19.3 \pm 2.5 \%$, respectively). Note that there is no difference in 
tumor progression between the two groups (T2 and T3) of sham treated rats, but these rats harbored tumors comparable with those in growth-kinetics Group K3 (19.9 \pm 0.9\%), which were killed on Day 21 following initial transplantation. c: No tumors but only small cavities (glial scars) that corresponded to the device's implantation site were measured in treatment control groups A1 and A2 (anti-CD44s mAb treated, $0.3 \pm 0.07 \%$, and isotype control $\mathrm{IgG}_{1}$ treated, $0.3 \pm 0.06 \%$, respectively), in which rats were monitored just for the effect of anesthesia and repeated instillations in the absence of transplanted C6 cells. Note that the scale on the ordinate is $\log 10$. $\mathrm{d}$ : Inhibition of C6 cell adhesion to glass coverslips that were precoated with laminin, fibronectin, or collagen after 18 hours of culture in the presence of graded concentrations of anti-CD44s mAb. The C6 cells were detached to $0 \%$ at 1.28 $\mu \mathrm{g} / \mathrm{well}$ or $2.56 \mu \mathrm{g} / \mathrm{well}$, to $11 \pm 2.1 \%$ at $5.12 \mu \mathrm{g} / \mathrm{well}$, to $31 \pm 3.1 \%$ at $7.68 \mu \mathrm{g} / \mathrm{well}$, to $59 \pm$ $2.9 \%$ at $10.24 \mu \mathrm{g} /$ well, and to $94 \pm 2.7 \%$ at $12.8 \mu \mathrm{g} /$ well. The C6 cells were detached to $0 \%$ after incubation with same the concentrations of isotype control $\mathrm{IgG}_{1}$, even at the highest dose of $12.8 \mu \mathrm{g} / \mathrm{well}$.

\section{Cytotoxicity Assay}

Even at the highest antibody concentration of $20 \mu \mathrm{g} / \mathrm{well}$ for both anti-CD44s mAb and isotype control $\mathrm{IgG}_{1}$, no cytotoxic effect was detected, as compared with controls incubated under the same conditions but in absence of antibodies (Fig. 3). 


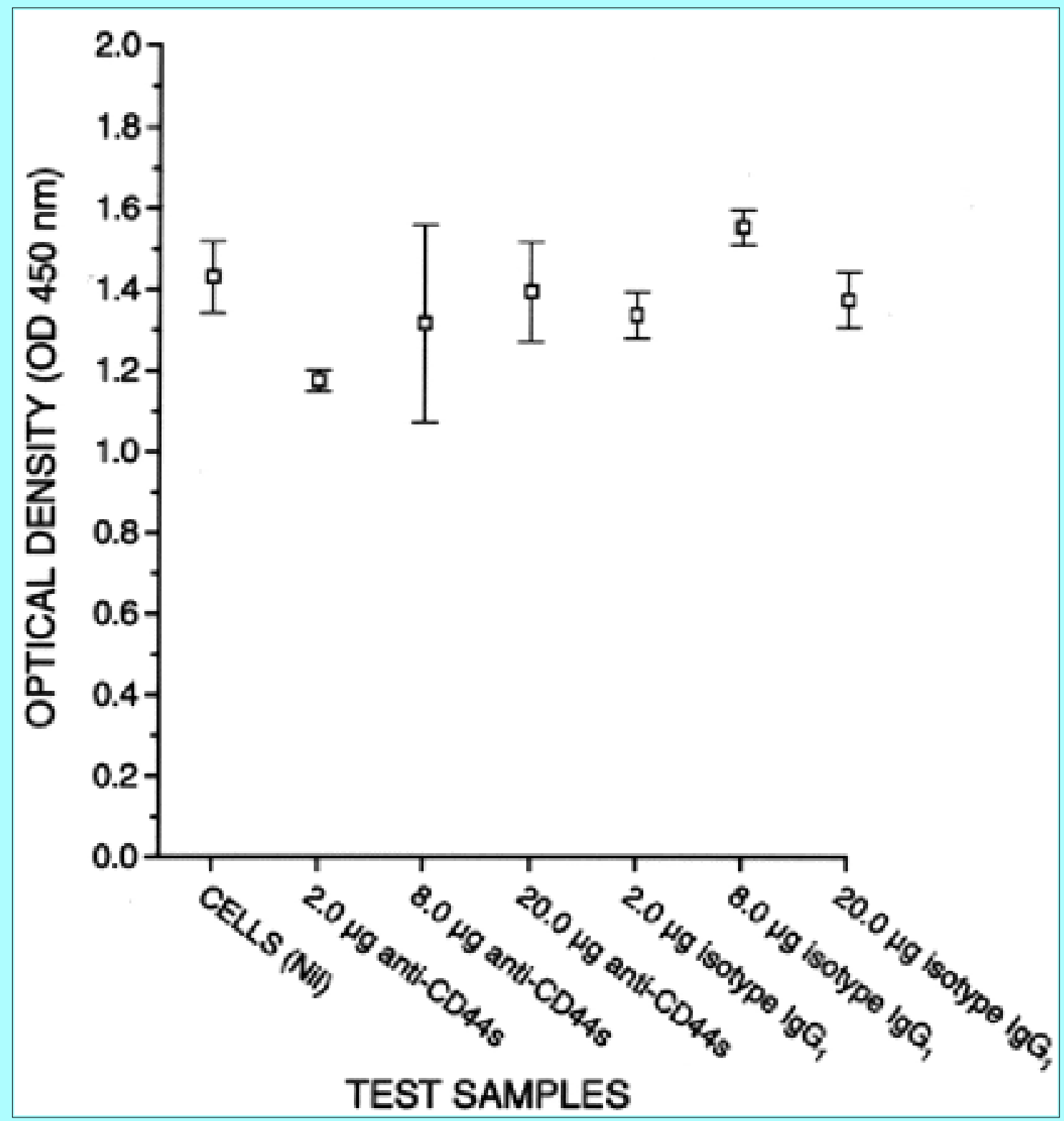

Fig. 3. Graph showing the effect of anti-CD44s $\mathrm{mAb}$ and isotype control $\mathrm{IgG}_{1}$ on the proliferation and viability of C6 cells. Values are expressed as the mean \pm SD. Statistical significance was set at $\mathrm{p}$ is less than 0.05 . Even at the highest antibody concentration of 20 $\mu \mathrm{g} /$ well for both anti-CD44s mAb or isotype control $\mathrm{IgG}_{1}$, no cytotoxic effect was detected, as compared with controls incubated under the same conditions but in the absence of antibodies.

\section{Disruption of Intracerebral Progression of C6 GBM by anti-CD44s mAb}

Intracerebral tumors grew as solid, highly invasive masses (Fig. $1 \mathrm{~g}$ ) with blurred delineation against host brain tissue. Tumor invasion of the host brain occurred mainly by diffuse infiltration of the white matter and to a much lesser extent by guided spread along brain blood vessels. Tumor progression in the growth-kinetics groups, $\mathrm{K} 1, \mathrm{~K} 2$, and $\mathrm{K} 3$ ( 7,14 , and 21 days following initial transplantation in absence of treatment; Table 1), showed typical exponential growth: $1.3 \pm 0.3 \%$ (SD) on Day 7, $6.3 \pm 1.1 \%$ (SD) on Day 14, and 19.9 $\pm 0.9 \%$ (SD) on Day 21 (Fig. 2 a). The rats in Group T1, which were treated with three successive doses (32 $\mu \mathrm{g}$ each) of anti-CD44s mAb on Days 7, 10, and 12 following initial transplantation (Table 1), harbored significantly smaller tumors (3.6 $\pm 0.4 \%$ [SD]) on Day 14 (Fig. 2 b), as compared with the tumors in the untreated rats in groups $\mathrm{K} 2(6.3 \pm 1.1 \%$ [SD]) or the sham-treated 
rats in groups T2 and T3 (19.2 $\pm 1.1 \%$ and $19.3 \pm 2.5 \%$ [SD], respectively), which were sacrificed on the same day, (Day 14; (Fig. 2 a and b). No differences in tumor progression were observed on day 14 between the two groups of sham-treated rats--that is, T2 (isotype control $\mathrm{IgG}_{1}$ treated; $19.2 \pm 1.1 \%[\mathrm{SD}]$ ) and T3 (PBS treated; $19.3 \pm 2.5 \%$ [SD]; Fig. 2 b). However, these rats harbored tumors comparable with those of the growth-kinetics Group K3 (19.9 $\pm 0.9 \%$ [SD]), which were sacrificed on Day 21 following initial transplantation (Fig. $2 \mathrm{a}$ and b). In treatment control Groups A1 (anti-CD44s mAb treated) and A2 (isotype control $\mathrm{IgG}_{1}$ treated), in which rats were monitored just for the effect of anesthesia and repeated instillations in absence of tumor (Table 1), only small cavities (glial scars) were measured $(0.3 \pm 0.07 \%$ and $0.3 \pm 0.06 \%$ [SD], respectively), that corresponded to the device's implantation site (Fig. 2 c).

\section{Effect of Treatment on Rat Weight}

In the daily monitoring of hydration and nutritional status of the rats significant differences between groups were revealed. Tumor progression in the growth-kinetics groups, K1, K2, and K3 (7, 14, and 21 days following initial transplantation in absence of treatment; (Table 1), correlated with a decrease in body weight: $168.0 \pm 3.2 \mathrm{~g}$ (SD) on Day 7, $137.0 \pm 4.7 \mathrm{~g}$ (SD) on Day 14, and $83.0 \pm 2.7 \mathrm{~g}$ (SD) on Day 21 (Fig. 4 a). Rats in Group T1, which were treated with three successive doses (32 $\mu \mathrm{g}$ each) of anti-CD44s mAb on Days 7, 10, and 12 following initial transplantation (Table 1), were significantly less cachectic (166.6 $\pm 16.4 \mathrm{~g}$ [SD]) on Day 14, as compared with the untreated rats of Group K2 (137.0 $\mathrm{g} \pm$ $4.7 \mathrm{~g}$ [SD]) or the sham-treated rats of Groups T2 and T3 $(83.4 \pm 1.1 \mathrm{~g}$ and $83.0 \pm 2.2 \mathrm{~g}$ [SD], respectively), which were sacrificed on the same day,--Day 14 (Fig. 4 b). No differences in body weight were observed on Day 14 between the two groups of sham-treated rats--that is, T2 (isotype control $\mathrm{IgG}_{1}$ treated, $83.4 \pm 1.1 \mathrm{~g}$ [SD]) and T3 (PBS treated, $83.0 \pm 2.2 \mathrm{~g}$ [SD]) (Fig. 4 b). However, these rats presented with body weights comparable with those of rats in the growth-kinetics Group K3 (83.0 2.7 g), that were sacrificed on Day 21 following initial transplantation (Fig. 4 a and b). Similarly, no differences in body weight were observed on Day 14 between the two treatment control groups A1 (anti-CD44s mAb treated, 176.0 $\pm 17.8 \mathrm{~g}$ [SD]) and A2 (isotype control $\mathrm{IgG}_{1}$ treated, 176.0 $\pm 20.4 \mathrm{~g}$ [SD]), in which rats were monitored just for the effect of anesthesia and repeated instillations in absence of tumor (Table 1 and Fig. 4 c). However, these rats presented with body weights comparable with those of the control group C2 $(210.0 \pm 23.5 \mathrm{~g}$ [SD]), which were monitored on the same day (Day 14; Fig. $4 \mathrm{c}$ and d). In the rats in control Groups C1, C2, and C3 (on Days 7, 14, and 21 following start of experimental phase), which were monitored just for hydration and nutritional status in the absence of anesthesia, C6 cell transplantation, and treatment (Table 1), a progressive increase in body weight was shown: C1 (on Day 7, 196.6 $\pm 29.3 \mathrm{~g}$ [SD]), C2 (Day 14, $210.0 \pm 23.5 \mathrm{~g}$ [SD]), and C3 (Day 21, $225.0 \pm$ $28.3 \mathrm{~g}[\mathrm{SD}])$ as compared with all other groups (Fig. $4 \mathrm{~d}$ ). 

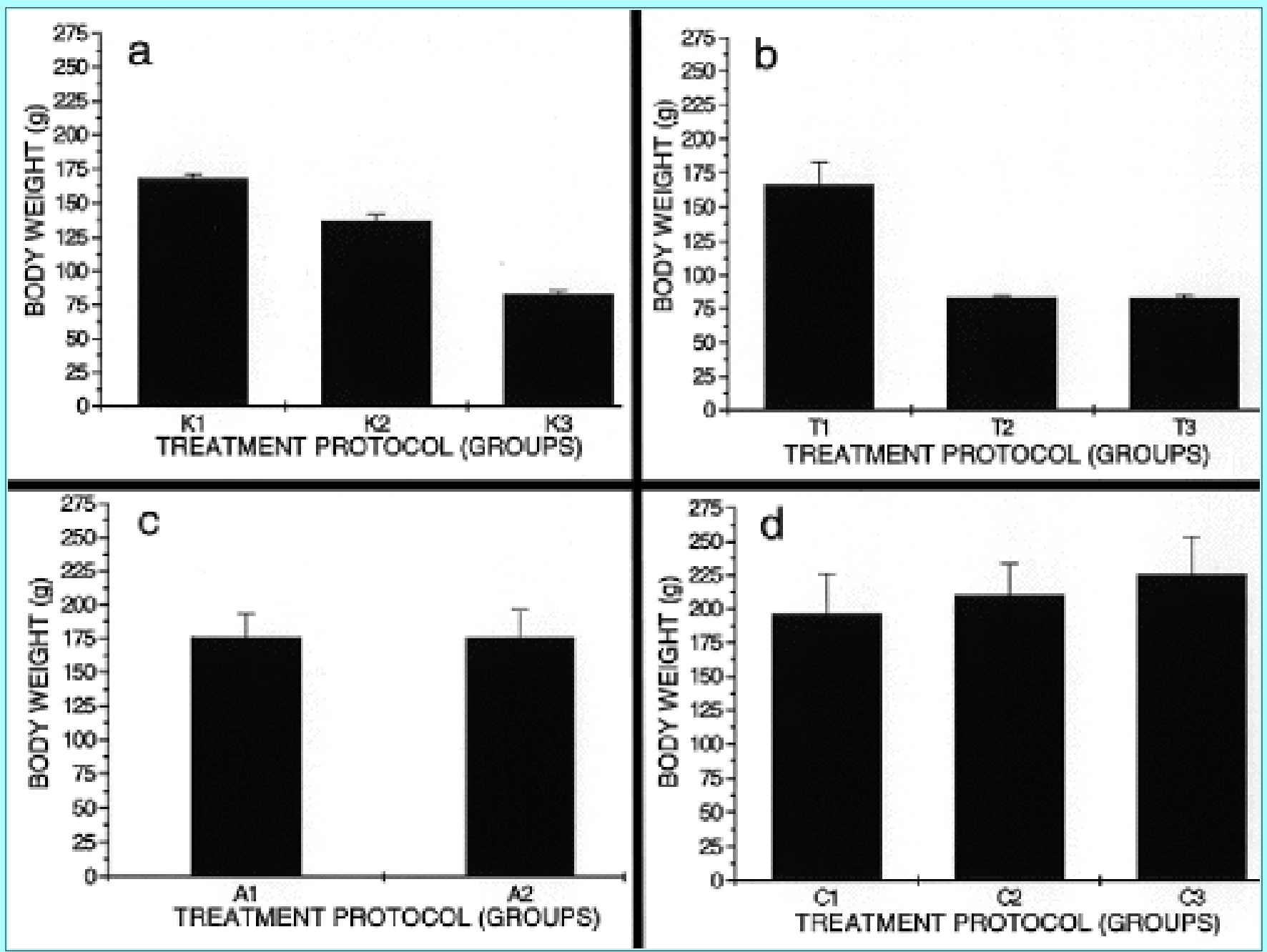

Fig. 4. Graphs showing the body weights of treated, sham-treated, and control rats. All values are expressed as the mean values \pm SD. Statistical significance was set at $p$ is less than 0.05. a: Tumor progression in growth-kinetics groups, $\mathrm{K} 1, \mathrm{~K} 2$, and $\mathrm{K} 3$ (7, 14, and 21 days following initial transplantation in the absence of treatment), correlated with a decrease in body weight $(168.0 \pm 3.2 \mathrm{~g}$ on Day $7,137.0 \pm 4.7 \mathrm{~g}$ on Day 14 , and $83.0 \pm 2.7 \mathrm{~g}$ on Day 21). b: Rats in group T1, which were treated with three successive doses (32 $\mu \mathrm{g}$ each) of anti-CD44s mAb on Days 7, 10, and 12 following initial transplantation, were significantly less cachectic (166.6 $\pm 16.4 \mathrm{~g})$ on Day 14, as compared with the untreated rats in Group K2 $(137.0 \pm 4.7 \mathrm{~g})$ or the sham-treated rats in Groups T2 and T3 $(83.4 \pm 1.1 \mathrm{~g}$ and $83.0 \pm 2.2 \mathrm{~g}$, respectively). Note that there is no difference in body weight on Day 14 between the two groups of sham-treated rats (isotype control $\mathrm{IgG}_{1}$ treated [T2], $83.4 \pm 1.1 \mathrm{~g}$, and PBS treated [T3], $83.0 \pm 2.2 \mathrm{~g}$, respectively). However, these rats presented with body weights comparable with those of growth-kinetics Group K3 $(83.0 \pm 2.7 \mathrm{~g})$, which were killed on Day 21 following initial transplantation. c: No differences in body weight were observed on Day 14 between the two treatment control groups (anti-CD44s mAb treated [A1], $176.0 \pm$ $17.8 \mathrm{~g}$; and isotype control $\mathrm{IgG}_{1}$ treated [A2], $176.0 \pm 20.4 \mathrm{~g}$, respectively), in which rats were monitored just for the effect of anesthesia and repeated instillations in absence of transplanted C6 cells. However, these rats presented with body weights comparable with those of control Group C2 $(210.0 \pm 23.5 \mathrm{~g})$, which were monitored on the same day (Day 14). d: In rats in control Groups, $C 1, C 2$, and $C 3$ (7, 14, and 21 days following start of experimental phase), which were monitored just for hydration and nutritional status in the 
absence of anesthesia, C6 cell transplantation, and treatment, a progressive increase in body weight was shown: C1 (Day 7, 196.6 $\pm 29.3 \mathrm{~g}$ ), C2 (Day 14, $210.0 \pm 23.5 \mathrm{~g}$ ), and C3 (Days $21,225.0 \pm 28.3 \mathrm{~g}$ ) as compared with all other groups.

\section{DISCUSSION}

The mechanisms involved in ECM-dependent glioma cell migration are still poorly understood, although there is a strong body of evidence that HA plays a critical role in promoting migration in human gliomas.[6] Invasive behavior of glioma cells mediated by interaction of HA with CD44s (over)-expressed on their surface was demonstrated in vitro in primary cultures obtained from biopsy material by inhibition of migration and invasion with an anti-CD44s antibody.[6] Similar results were obtained with eight established glioma cell line.[24] However, there is clear evidence of only partial inhibition of invasion by anti-CD44s antibodies, thus suggesting that HA receptors other than CD44s are likely to be involved in HA-dependent invasion of glioma cells.[15,41] Furthermore, because HA is not a unique ligand for $\mathrm{CD} 44$, other major components of the ECM may participate in glioma cell invasiveness as well.[7,12,19,30] Our data demonstrate that interactions between CD44s, and its natural (ligands laminin, fibronectin, and collagen) are disrupted by an anti-CD44s mAb. Incubation of C6 GBM cells with anti-CD44s mAb 18 hours following initial adhesion caused a dose-dependent detachment of the cells from the ECM-coated culture surface. Binding saturation of anti-CD44s to the receptor occurred at $1 \mu \mathrm{g}$, and 18 hours of in vitro incubation with $12.8 \mu \mathrm{g}$ anti-CD44s mAb was sufficient to induce almost complete detachment of C6 GBM cells. This effect was similar for all three ECM components, thus supporting the major role played by CD44s in glioma cell adhesion and invasion. Furthermore, despite the fact that no cytotoxic effect of anti-CD44 mAb was detected, inhibition of adhesion was highly specific, because the matched isotype control $\mathrm{IgG}_{1}$ showed no effect.

It has been shown that binding of CD44s to HA is dependent on ankyrin binding to its cytoplasmatic domain, which appears to be regulated by protein kinase $\mathrm{C}$-mediated phosphorylation, palmitylation, and guanosine 59-triphosphate binding.[29] The closely association of the cytoplasmic domain of CD44 with actin filaments[17,18,22,26,40] and the organization of the latter into stress fiber arrays indicate the role played by CD44 in cytoskeletal rearrangement during active glioma cell migration.[16] This correlates with fast brain-tumor progression, as shown in our study. Thus, in addition to participating in cellular adhesion, CD44s may function as a signal-transducing molecule that promotes glioma cells to produce autocrine and paracrine growth factors. Such cytokines are critical for tumor progression, because initial adhesion of tumor cells to ECM is followed by angiogenesis.[38] Analysis of our data demonstrates that strong expression of CD44s correlated with rapid tumor growth and invasion of host brain tissue. Progression (that is, invasion and growth) of intracerebral C6 tumors was strongly inhibited by only three local instillations of anti-CD44s mAb, which supports the observation that tumor progression is dependent on adhesion to ECM. In the case of malignant melanoma, interactions between CD44s and its ligands are seemingly critical not only for tumor progression but for metastasis as well, and treatment with an anti-CD44s antibody blocks the latter.[13] Analysis of other findings, on the other hand, demonstrated that treatment of melanoma cells with an anti-CD44s mAb blocking the receptor increased their metastatic ability and adhesiveness.[33] Analysis of our data shows that local treatment of intracerebral C6 tumors, which was begun 1 week following transplantation and thus allowing initial growth, and was conducted for 1 additional week, was efficient to stop tumor progression. Therefore, treated tumors reached only approximately half of the total cross-sectional area on Day 14, as compared with tumors obtained from untreated or sham-treated animals. This effect is consistent with other 
findings that show specific blocking of melanoma progression and metastasis by treatment with an anti-CD44s antibody.[13] The major difference, besides the cell line used, between the former study and our findings is the fact that anti-CD44s had to be given either on the same day or no later than 3 days after melanoma cell injection to achieve significant inhibition. This discrepancy may be explained by the fact that different clones of melanoma cells differently select for CD44s expression, [13,32] and melanomas may express particular CD44 splice variants, that confer metastatic potential, whereas gliomas do not. Furthermore, this could be one reason why the latter tumors do not metastasize. However, authors of other reports have shown that CD44v is expressed, although at very low levels, in a small fraction of some primary and established glioma cell lines.[8,21] These observations are of great interest because metastases display, in most cases, a macro- and microscopically sharp delineation from the surrounding brain in contrast to gliomas, which diffusely infiltrate brain tissue.

A striking observation made in the present study is that intracerebral tumors obtained in Groups T2 and $\mathrm{T} 3$ that were sham treated with either isotype control $\mathrm{IgG}_{1}$ or PBS progressed significantly faster and thus reached similar areas on Day 14 as those untreated tumors obtained in group K3 on Day 21. We have previously reported a similar phenomenon in the case of intracerebral transplantation of U-87 GBM, suggesting a cytokine-mediated tumor growth-promoting effect of irrelevant substances (isotype control $\mathrm{IgG}_{1}$ or PBS).[38] This effect could be explained by the fact that repeated intratumoral instillations may stimulate glioma cells to release higher amounts of autocrine cytokines such as basic fibroblast growth factor. However, treatment of intracerebral C6 tumors with anti-CD44s mAb was highly efficient in inhibiting tumor progression, thus prevailing over growth-promoting "side-effects."

The glioma model used in the present study is artificial, and the specific anti-CD44s monoclonal antibody that was intratumorally injected most likely reacted with CD44s epitopes constitutively expressed on normal non-neoplastically transformed glial cells as well.[2,11,32] The cross-reactivity of the anti-CD44s antibody used in the present study with CD44 isoforms constitutively expressed on neurons, axonal membranes, endothelium, and choroid plexus (that is, CD44v4, CD44v5, CD44v6, and CD44v10) could be excluded by microscopic examination of immunohistochemically stained brain sections. A lack of cross-reactivity of anti-CD44s antibodies with CD44 isoforms, and vice versa, of anti-CD44v antibodies with standard CD44 epitope has been previously demonstrated.[20] This specificity is explained by steric or conformational obstruction of the various CD44 epitopes depending on the degree of glycosilation.[23,27]

In aggregate, our data can be used to demonstrate that local treatment with an anti-CD44s monoclonal antibody an efficiently disrupt glioma progression and does not affect the treated rats. On the contrary, treated animals presented with less tumor-induced cachexia as compared with the control rats, thus suggesting a protective effect of the treatment. Although continuous delivery and long-term extracellular persistence of anti-CD44 antibodies effectively disrupted glioma progression, the treatment failed to cure brain tumors. This may be explained by the fact that either the antibody was rapidly degraded within the tumor and tumor environment or/and the tumor could rapidly "compensate" for treatment by overexpressing CD44. Current studies in our laboratory are aimed at elucidating this phenomenon by using micellary encapsulated phosphorothioated antisense oligodeoxynucleotides to CD44s mRNA in glioma cells (Beutel, G., et al., unpublished data).

\section{Acknowledgments}

This work was supported by Grant No. Sta 429/21 from the Deutsche Forschungsgemeinschaft to 
A.C.S.). Confocal laser scanning microscopy was performed at the MSSM-CLSM core facility, supported with funding from the National Institutes of Health shared instrumentation Grant No. 1 S10 RR0 914501 and National Science Foundation Major Research Instrumentation Grant No. DBI9724504.

We thank Mrs. D. Dudacy, Mrs. E. Sikora, Mr. U. Preiss, Mr. G. Braun, and Mrs. C. Pütz, Institute of Neuropathology, Hannover Medical School, Hannover, Germany, for excellent technical assistance; Mrs. Veronica Gulle and Ms. Ameera Ali, Department of Pathology, Mount Sinai School of Medicine, New York, NY, for excellent technical assistance; and Dr. A. Miller for critical review of the manuscript.

\section{References}

1. Aruffo A, Stamenkovic I, Melnick M, et al: CD44 is the principal cell surface receptor for hyaluronate. Cell 61:1303-1313, 1990

2. Asher R, Bignami A: Hyaluronate binding and CD44 expression in human glioblastoma cells and astrocytes. Exp Cell Res 203:80-90, 1992

3. Baltuch GH, de Tribolet N, van Meir EG: Expression of the CD44 adhesion molecule in tumours of the central and peripheral nervous system. J Neurooncol 26:191-198, 1995

4. Bartolazzi A, Peach R, Aruffo A, et al: Interaction between CD44 and hyaluronate is directly implicated in the regulation of tumor development. J Exp Med 180:53-66, 1994

5. Berg EL, Goldstein LA, Jutila MA, et al: Homing receptors and vascular addressins: cell adhesion molecules that direct lymphocyte traffic. Immunol Rev 108:5-18, 1989

6. Bouterfa H, Janka M, Meese E, et al: Effect of changes in the CD44 gene on tumour cell invasion in gliomas. Neuropathol Appl Neurobiol 23:373-379, 1997

7. Carter WG, Wayner EA: Characterization of the class III collagen receptor, a phosphorylated, transmembrane glycoprotein expressed in nucleated human cells. J Biol Chem 263:4193-4201, 1988

8. Eibl RH, Pietsch T, Moll J, et al: Expression of variant CD44 epitopes in human astrocytic brain tumors. J Neurooncol 26:165-170, 1995

9. Flanagan BF, Dalchau R, Allen AK, et al: Chemical composition and tissue distribution of the human CDw44 glycoprotein. Immunology 67:167-175, 1989

10. Girgrah N, Ackerley CA, Moscarello MA: Localization of CD44 (P80) on the external surface of a human astrocytoma cell. Neuroreport 2:441-444, 1991

11. Girgrah N, Letarte M, Becker LE, et al: Localization of the CD44 glycoprotein to fibrous astrocytes in normal white matter and to reactive astrocytes in active lesions in multiple sclerosis. J Neuropathol Exp Neurol 50:779-792, 1991

12. Goldstein LA, Zhou DF, Picker LJ, et al: A human lymphocyte homing receptor, the hermes antigen, is related to cartilage proteoglycan core and link proteins. Cell 56:1063-1072, 1989

13. Guo Y, Ma J, Wang J, et al: Inhibition of human melanoma growth and metastasis in vivo by anti-CD44 monoclonal antibody. Cancer Res 54:1561-1565, 1994 
14. Haegel H, Tolg C, Hofmann M, et al: Activated mouse astrocytes and T cells express similar CD44 variants. Role of CD44 in astrocyte/T cell binding. J Cell Biol 122:1067-1077, 1993

15. Hall CL, Yang B, Yang X, et al: Overexpression of the hyaluronan receptor RHAMM is transforming and is also required for H-ras transformation. Cell 82:19-26, 1995

16. Hedberg KK, Birrell GB, Mobley PL, et al: Transition metal chelator TPEN counteracts phorbol ester-induced actin cytoskeletal disruption in C6 rat glioma cells without inhibiting activation or translocation of protein kinase C. J Cell Physiol 158:337-346, 1994

17. Jacobson K, O'Dell D, August JT: Lateral diffusion of an 80,000-dalton glycoprotein in the plasma membrane of murine fibroblasts: relationships to cell structure and function. J Cell Biol 99:1624-1633, 1984

18. Jacobson K, O'Dell D, Holifield B, et al: Redistribution of a major cell surface glycoprotein during cell movement. J Cell Biol 99:1613-1623, 1984

19. Jalkanen S, Jalkanen M: Lymphocyte CD44 binds the COOH-terminal heparin-binding domain of fibronectin. J Cell Biol 116:817-825, 1992

20. Kaaijk P, Pals ST, Morsink F, et al: Differential expression of CD44 splice variants in the normal human central nervous system. J Neuroimmunol 73:70-76, 1997

21. Kaaijk P, Troost D, Morsink F, et al: Expression of CD44 splice variants in human primary brain tumors. J Neurooncol 26:185-190, 1995

22. Kalomiris EL, Bourguignon LY: Lymphoma protein kinase $\mathrm{C}$ is associated with the transmembrane glycoprotein, GP85, and may function in GP85-ankyrin binding. J Biol Chem 264:8113-8119, 1989

23. Katoh S, Zheng Z, Oritani K, et al: Glycosylation of CD44 negatively regulates its recognition of hyaluronan. J Exp Med 182:419-429, 1995

24. Koochekpour S, Pilkington GJ, Merzak A: Hyaluronic acid/CD44H interaction induces cell detachment and stimulates migration and invasion of human glioma cells in vitro. Int $\mathbf{J}$ Cancer 63:450-454, 1995

25. Kuppner MC, van Meir E, Gauthier T, et al: Differential expression of the CD44 molecule in human brain tumours. Int J Cancer 50:572-577, 1992

26. Lacy BE, Underhill CB: The hyaluronate receptor is associated with actin filaments. J Cell Biol 105:1395-1404, 1987

27. Lesley J, English N, Perschl A, et al: Variant cell lines selected for alterations in the function of the hyaluronan receptor CD44 show differences in glycosylation. J Exp Med 182:431-437, 1995

28. Lesley J, Schulte R, Hyman R: Binding of hyaluronic acid to lymphoid cell lines is inhibited by monoclonal antibodies against Pgp-1. Exp Cell Res 187:224-233, 1990

29. Lokeshwar VB, Fregien N, Bourguignon LY: Ankyrin-binding domain of CD44(GP85) is required for the expression of hyaluronic acid-mediated adhesion function. J Cell Biol 126:1099-1109, 1994

30. Merzak A, Koocheckpour S, Pilkington GJ: CD44 mediates human glioma cell adhesion and 
invasion in vitro. Cancer Res 54:3988-3992, 1994

31. Miyake K, Underhill CB, Lesley J, et al: Hyaluronate can function as a cell adhesion molecule and CD44 participates in hyaluronate recognition. J Exp Med 172:69-75, 1990

32. Moretto G, Xu RY, Kim SU: CD44 expression in human astrocytes and oligodendrocytes in culture. J Neuropathol Exp Neurol 52:419-423, 1993

33. Ota T, Matsui T, Kohno H, et al: CD44 participates in tumor cell adhesion to endothelial cells in the experimental metastatic process in B16BL6 melanoma cells. Anticancer Res 15:1215-1219, 1995

34. Picker LJ, de los Toyos J, Telen MJ, et al: Monoclonal antibodies against the CD44 [In(Lu)-related p80], and Pgp-1 antigens in man recognize the Hermes class of lymphocyte homing receptors. J Immunol 142:2046-2051, 1989

35. Picker LJ, Nakache M, Butcher EC: Monoclonal antibodies to human lymphocyte homing receptors define a novel class of adhesion molecules on diverse cell types. J Cell Biol 109:927-937, 1989

36. Radotra B, McCormick D, Crockard A: CD44 plays a role in adhesive interactions between glioma cells and extracellular matrix components. Neuropathol Appl Neurobiol 20:399-405, 1994

37. Screaton GR, Bell MV, Bell JI, et al: The identification of a new alternative exon with highly restricted tissue expression in transcripts encoding the mouse Pgp-1 (CD44) homing receptor. Comparison of all 10 variable exons between mouse, human, and rat. J Biol Chem 268:12235-12238, 1993

38. Stan AC, Nemati MN, Pietsch T, et al: In vivo inhibition of angiogenesis and growth of the human U-87 malignant glial tumor by treatment with an antibody against basic fibroblast growth factor. J Neurosurg 82:1044-1052, 1995

39. Sy MS, Guo YJ, Stamenkovic I: Distinct effects of two CD44 isoforms on tumor growth in vivo. J Exp Med 174:859-866, 1991

40. Tarone G, Ferracini R, Galetto G, et al: A cell surface integral membrane glycoprotein of $85,000 \mathrm{~mol}$ wt (gp85) associated with triton X-100-insoluble cell skeleton. J Cell Biol 99:512-519, 1984

41. Turley EA: Hyaluronan and cell locomotion. Cancer Metastasis Rev 11:21-30, 1992

42. Vogel H, Butcher EC, Picker LJ: H-CAM expression in the human nervous system: evidence for a role in diverse glial interactions. J Neurocytol 21:363-373, 1992

43. Zhou DF, Ding JF, Picker LJ, et al: Molecular cloning and expression of Pgp-1. The mouse homolog of the human H-CAM (Hermes) lymphocyte homing receptor. J Immunol 143:3390-3395, 1989

Manuscript received January 15, 1999.

Accepted in final form July 1, 1999.

Address reprint requests to: Alexandru C. Stan, M.D., Ph.D., the Institute of Neuropathology, Hannover Medical School, Carl-Neuberg-Strasse 1, 30625 Hannover, Germany. email: stan.alex@ mh-hannover.de. 